Introducing RDA: 2, Resource Description, July 5-6 or August 30-31, (http://www.lyrasis.org/?sc itemid=\%7b3DEF61AA-2111-4E08-B992EB0650DB8D13\%7d\&RowId=1-LW3ZK)

RDA: On the Road to Implementation, May 51 or July 7 or August 4, (http://www.lyrasis.org/?sc itemid=\%7b15B77F67-7DEA-4B30-A80291AC9D20558E\%7d\&RowId=1-LVK2T)

\title{
ATLA CONFERENCE JUNE 2011 TECHNICAL SERVICES
}

\section{Tuesday (June 7)}

7:00 PM-9 PM

Interest Group

Topic: What I Wish I had Known When I Started in Technical Services - TSIG

\section{Wednesday (June 8)}

8:30 AM-12 PM

Pre-Conference Workshop-Morning

Tackling the Foreign-Language Backlog: Roman-Script Languages and Introduction to Romanization

1:00 PM-4:30 PM

Pre-Conference Workshop-Afternoon

Tackling the Foreign-Language Backlog: Advanced Romanization

\section{Thursday (June 9)}

Conversation Groups

10:30 AM-11:30 AM

Library of Congress Genre/Form Project Update

Name Authority Conversation Group 
1:00 PM-2:00 PM

Conversation Group

CONSER Conversation Group

Paper

2:00 PM-3:00 PM

Second Harvest-Digitizing Church and Denominational Materials

\section{Friday (June 9)}

10:30 AM-12 PM

In-Conference Workshop

Cataloging with RDA

1:30 PM-3 PM

Interest Group

Cost-Cutting Measures in Technical Services - TSIG

\section{SELECTED ARTICLES FROM CURRENT LIBRARY JOURNALS}

Collins, Maria. "Serials Literature Review 2008-9: Embracing a Culture of Openness." Library Resources \& Technical Services 55, no. 2 (April 2011): 60-80.

Digby, Todd, and Stephen Elfstrand. "Discovering Open Source Discovery: Using VuFind to Create MnPALS Plus.” Computers in Libraries 31, no. 2 (March 2011): 6-10.

Emanuel, Jennifer. "Usability of the VuFind Next-Generation Online Catalog." Information Technology and Libraries 30, no. 1 (March 2011): 44-52.

Galvin, Denis, and Mang Sun. “Using Web Services for a Mobile OPAC.” Code4Lib Journal 13 (2011-04-11). http://journal.code4lib.org/articles/4810 (accessed April 20, 2011)

Jacob, Elin K. "Proposal for a Classification of Classifications built on Beghtol's Distinction between 'Naïve Classification' and 'Professional Classification.'” Knowledge Organization 37, no. 2 (2010): 111-120.

Krishnan, Yvonne. "Libraries and the Mobil Revolution." Computers in Libraries 31, no. 3 (April 2011): 6-9, 40. 